\title{
Commentary by Yiannis Laouris
}

\author{
Yiannis Laouris
}

Working towards this Manifesto has been a most inspiring experience; being among philosophers in this think tank, I was initially somewhat skeptical as to the feasibility of quite different-minded scientists, some with very strong views, managing to converge on a text that satisfactorily draws attention to key concepts that require reengineering. I especially enjoyed the fact that, like the ancient Athenians, we treated philosophy, science, and politics as strongly interconnected disciplines. Even if this is all that is learned from our work, the world will benefit tremendously!

The Manifesto reflects my personal views, which is why I have endorsed it. In my chapter, I elaborate on the need to re-engineer the concept of life and how the emerging immortality of artifacts and information exerts pressure on achieving immortality of the mind and/or of the human; the blurring of concepts like "being human" or "being alive." In this short commentary, however, I chose to draw special attention to the risks created by the feasibility of direct democracy as encapsulated in $\S 1.4$ because of their urgency:

$\S 1.4 \ldots$ By ... opening new possibilities for direct democracy, ICTs destabilize and call for rethinking the worldviews and metaphors underlying modern political structures.

In the chapters' section, I elaborate on the requirements of technologies needed to reinvent democracy in the digital era, especially in light of the virtual immortality and abundance of information, which inevitably result in cognitive overload, as reflected here:

$\S 2.3$ The abundance of information may also result in cognitive overload, distraction...

Democracy in the twenty-first century has come to refer almost exclusively to the right to take part in the political process, i.e., the right to vote. Since ICTs open up tremendous possibilities for real-time feedback and frequent polling, in the minds of many, extra voting equals more democracy. "Direct Democracy" is a term coined

\footnotetext{
Y. Laouris $(\bowtie)$

Future Worlds Center, Cyprus Neuroscience \& Technology Institute, Nicosia, Cyprus

e-mail: Laouris@futureworldscenter.org

5 Promitheos, 1065 Lefkosia, Cyprus

L. Floridi (ed.), The Onlife Manifesto, 
recently, referring to a specific (one of many) model of democratic participation in which all members have equality of access, vote, and voice on every issue. The adoption of such an approach in taking political or other decisions would undoubtedly cause chaos. It should therefore be rigorously distinguished and differentiated from massive but authentic democratic participation. The latter demands that all relevant stakeholders be given the opportunity to participate and a voice to argue over the issues that influence their lives. Votes should be weighted in some way in order to ensure that decisions take advantage of what we call "collective wisdom." This is not a trivial problem to solve. Identifying who the "relevant" stakeholders are and deciding who should have a (weighted) vote on which matters is extremely complex. Even when the theoretical challenges are resolved, we will need to develop systems that implement the theory.

Athenians of the Golden Age were engaged collectively in searching and carefully examining meanings and alternatives together through a process they called "deliberation." They aimed to fully understand the underlying problems, clarify the debatable situation, and achieve consensus. More than two millennia later, we need to reinvent democracy in such a way that millions can participate effectively. We must guarantee that the individual will have access to all relevant information, alternatives, arguments, and predicted futures that might emerge according to the choices s/he makes. We will probably need to invent new liquid forms of democracy in which ideas can flow from crowds and are shaped through a process of open deliberation. Future citizens should somehow become capable of choosing alternatives by harvesting their collective intelligence and wisdom rather than allowing the personal interests and pathetic behaviors of individuals to prevail in the decisionmaking process. Since technology will be absolutely essential, the democratization of the processes of design and development of such new technologies also becomes a fundamental requirement. In addition, we must guarantee access and simplicity of interfaces.

In sum, we should design spaces and technologies and implement policies that respect our cognitive constraints, safeguard our attention capabilities, and secure our individual human rights and freedoms. We ought to develop systems that guarantee the authentic participation of those whose lives might be influenced by any decisions taken. Courses of action should be chosen based on their capacity to facilitate change toward a collectively defined, desired, and agreed-upon ideal future state.

Open Access This chapter is distributed under the terms of the Creative Commons Attribution Noncommercial License, which permits any noncommercial use, distribution, and reproduction in any medium, provided the original author(s) and source are credited. 